\title{
Preparation of a Modified Nanoalumina Sorbent for the Removal of Alizarin Yellow $R$ and Methylene Blue Dyes from Aqueous Solutions
}

\author{
Wasan T. Al-Rubayee, Omar F. Abdul-Rasheed, and Noor Mustafa Ali \\ Department of Chemistry and Biochemistry, College of Medicine, Al-Nahrain University, P.O. Box 70027, Baghdad, Iraq \\ Correspondence should be addressed to Omar F. Abdul-Rasheed; omar_rasheed39@yahoo.com
}

Received 4 June 2016; Revised 12 August 2016; Accepted 18 October 2016

Academic Editor: Shayessteh Dadfarnia

Copyright (C) 2016 Wasan T. Al-Rubayee et al. This is an open access article distributed under the Creative Commons Attribution License, which permits unrestricted use, distribution, and reproduction in any medium, provided the original work is properly cited.

\begin{abstract}
A modified form of $\gamma$-alumina nanoparticles prepared by immobilization of 2,4-dinitrophenyl hydrazine on $\gamma$-alumina nanoparticles coated with sodium dodecyl sulfate (DNPH- $\gamma$-alumina) for the removal of the anionic dye (Alizarin yellow R) and cationic dye (Methylene blue) from aqueous solutions has been investigated. The FTIR, SEM, TEM, XRD, BET, and BJH analysis techniques indicate that the modification reaction has occurred. Batch adsorption study revealed that $0.05 \mathrm{~g}$ amount of the modified adsorbent was capable of removing $95.6 \%$ and $65.6 \%$ of Alizarin yellow (AY) and Methylene blue (MB) dyes, respectively, in $60 \mathrm{~min}$. The experimental equilibrium data showed that Langmuir isotherm applies well for describing the adsorption behavior, and the maximum adsorption capacity was found to be $47.8 \mathrm{mg} / \mathrm{g}$ and $32.8 \mathrm{mg} / \mathrm{g}$ for AY and MB on DNPH- $\gamma$-alumina, respectively. Kinetic studies showed best applicability of the second-order kinetic model. The DNPH- $\gamma$-alumina adsorbent proved capability, effectiveness, and selectivity for the removal of Alizarin yellow R dye. Therefore, it is possible to increase the efficiency of an adsorbent for the removal of pollutants by applying a modification to the surface of the adsorbent, and DNPH as a modifier proved efficient for the removal of a wider range of pollutants including metal ions and dye compounds.
\end{abstract}

\section{Introduction}

The environment is important for the public because most of our ecological systems like air, water, and soil are continuously being contaminated by domestic and industrial pollutants [1]. Dyes are the major pollutants that are used widely in textile, rubber, paper, distillery, plastic, cosmetics, and metal industries [2]. It was estimated that $2 \%$ of $7 \times 10^{5}$ tons of dyes every year were discharged in effluents from manufacturing operations, while $10 \%$ was discharged from textile and other associated industries [3]. The biodegradation of dye compounds is very difficult because of their complex chemical structures which have substituted chromophoric groups like azo, anthraquinone, triarylmethane, and so forth, and these dyes can decompose into carcinogenic aromatic amines under anaerobic conditions; therefore, the discharge of the dye containing effluents into waters can cause harmful effects such as allergic dermatitis, skin irritation, mutations, and cancer [4]. Therefore, dye containing effluents need to be treated before their discharge into the environment [5]. Adsorption is one of the most promising, favorable, and widely used method for the removal of pollutants from contaminated waters [6]. Recently, the use of nanoparticles for the removal of pollutants has become an interesting area of research due to their unique properties which are opening unprecedented opportunities and cost effective approaches; therefore various nanoparticles have been studied for this purpose [7-10]. Alumina is a well-known adsorbent and the form of $\gamma$-alumina is found to be more adsorptive in its activity than $\alpha$-alumina [11]. Gamma-alumina nanoparticles are promising materials as solid-phase adsorbents because of their large specific surface area, high adsorption capacity, mechanical strength, and low temperature modification [1214]. To increase the adsorption efficiency, chemical or physical modifications can be made on the surface of $\gamma$-alumina nanoparticles with compounds having functional groups that 
contain some donor atoms like oxygen, nitrogen, sulfur, or phosphorus [15-17]. 2,4-Dinitrophenyl hydrazine immobilized on sodium dodecyl sulfate- $\gamma$-alumina has been used for the coordination and removal of metal ions $[18,19]$ but to our knowledge its use for the interaction with dye compounds has not been studied. In this study the difference in the adsorption behavior of an anionic dye, Alizarin yellow $\mathrm{R}$ (AY), and cationic dye, Methylene blue (MB), on the modified DNPH- $\gamma$-alumina was investigated.

\section{Materials and Methods}

The Fourier Transform Infrared Spectroscopy (FTIR) of adsorbent was carried out with an FTIR-Alpha/Bruker/UK spectrophotometer. BET and BJH analysis for surface area measurement were obtained by $\mathrm{N}_{2}$ adsorption-desorption using Quantachrome/NOVA instrument. X-ray diffractometry using an X'PERT PRO PANalytical/Netherlands with $\mathrm{Cu}-\mathrm{K}_{\alpha}$ radiation. Scanning Electron Microscope (SEM) is carried out by using Inspect S50 (FET)/US scanning electron micrograph and Transmission Electron Microscope (TEM) analysis using Zeiss-EM10C-80 KV/Germany. The $\mathrm{pH}_{\mathrm{zpc}}(\mathrm{pH}$ zero point charge) was determined by a method mentioned previously [20]. The $\mathrm{pH}$ of dye solutions and $\mathrm{pH}_{\mathrm{zpc}}$ were determined by using $\mathrm{pH}$ Meter/HI 2211, HANAA/UK instrument. Absorbance measurements for the dyes solutions were carried out using a double beam UV-Vis spectrophotometer (UV-1800) Shimadzu/Japan. All reagents in this study were used without further purification. Alizarin yellow R (AY) was purchased from SCRC/China and Methylene blue (MB) from $\mathrm{BDH}$; 2,4-dinitrophenyl hydrazine was obtained from Fluka chemicals/Germany and sodium dodecyl sulfate (SDS) from Sigma/USA.

2.1. Preparation of Dyes Solutions. These dyes show maximum absorption $\left(\lambda_{\max }\right)$ at $362 \mathrm{~nm}$ and $664 \mathrm{~nm}$ for Alizarin yellow (AY) and Methylene blue (MB), respectively. $1000 \mathrm{mg}$ / L solutions of each dye were prepared by dissolving appropriate amount of dye in distilled water and stored in dark bottle and diluted by adding suitable amount of distilled water to the stock solutions as required. As an initial step of this investigation, a calibration curve is constructed for Alizarin yellow $\mathrm{R}$ dye and for Methylene blue dye by preparing different concentrations of each dye solutions and then measuring their absorbance using a double beam UV-Vis spectrophotometer each dye is measured at its specific $\lambda_{\text {max }}$. These dyes were found to obey Beer's law as shown in Figure 1. From these curves the concentration of the dyes in the solutions was obtained.

2.2. Adsorbent Preparation. Gamma-alumina nanopowder $\left(\gamma-\mathrm{Al}_{2} \mathrm{O}_{3}\right)$ was purchased from Sigma-Aldrich/USA with particle size $<50 \mathrm{~nm}$ and used without more purification.

The modified DNPH- $\gamma$-alumina was prepared by a method that immobilizes 2,4-dinitrophenyl hydrazine on the admicelles and hemimicelles of $\gamma$-alumina coated with sodium dodecyl sulfate as follows: each $2.0 \mathrm{~g}$ of $\gamma$-alumina nanopowder was mixed with $50 \mathrm{~mL}$ of distilled water and $100 \mathrm{mg}$ of sodium dodecyl sulfate (SDS). Then, $20 \mathrm{~mL}$ of a solution of 2,4-dinitrophenyl hydrazine, DNPH $(0.90 \mathrm{~g}$ $\mathrm{DNPH}$ in concentrated $\mathrm{HCl}+$ acetonitrile), was added. This suspension was stirred at $60^{\circ} \mathrm{C}$ for 9 hours. The excess solvent of the mixture was evaporated using a rotary evaporator; the prepared particles were then filtered, washed with distilled water, air-dried, and finally stored in a closed bottle for subsequent use $[18,19]$.

2.3. Batch Adsorption Experiments. The adsorption of the dye solutions was studied using the batch method due to its simplicity. All experiments were carried out in triplicate and average absorbance values were taken.

2.4. Effect of $p H$. The solutions were not buffered in order to mimic industrial practices. Experiments were carried out with the $\mathrm{pH}$ range of 4-11 for the dye solutions. In an Erlenmeyer flask, $0.05 \mathrm{~g}$ sample of each adsorbent was suspended in $50 \mathrm{~mL}$ solution of $50 \mathrm{mg} / \mathrm{L}$ of each dye solution at several $\mathrm{pH}$ values $(4,7,9$, and 11) using either $0.1 \mathrm{M}$ $\mathrm{NaOH}$ or $0.1 \mathrm{M} \mathrm{HCl}$ for $\mathrm{pH}$ adjustment. The flasks were covered and then placed on a mechanical shaker at a speed of $70 \mathrm{rpm}$ at room temperature. The resultant solutions were centrifuged at $2500 \mathrm{rpm}$ for 5 minutes, and then the residual dye concentrations of each solution were determined by measuring their absorbance.

2.5. Effect of Adsorbent Dose. The adsorbent dose of 0.02$0.2 \mathrm{~g}$ of each adsorbent was agitated for two hours with $50 \mathrm{~mL}$ of $50 \mathrm{mg} / \mathrm{L}$ dye solutions and at optimum $\mathrm{pH} 4$ for $\mathrm{AY}$ and $\mathrm{pH}$ 11 for MB. The resultant solutions were centrifuged, and the residual dye concentrations were determined.

2.6. Equilibrium Time Determination. $50 \mathrm{~mL}$ of initial concentration $(50 \mathrm{mg} / \mathrm{L})$ of $\mathrm{AY}$ and $\mathrm{MB}$ solutions was shaken with $0.05 \mathrm{~g}$ of each adsorbent at $\mathrm{pH} 4$ (AY) and $\mathrm{pH} 11$ (MB). The absorbance of the dye solutions was measured at different time intervals 10, 20, 30, 60, 90, and 120 minutes.

2.7. Effect of Temperature. The effect of temperature on the adsorption of $\mathrm{AY}$ and $\mathrm{MB}$ was studied by carrying out the temperature controlled equilibrium experiments, with varying temperatures $(293,298,308,318$, and $328 \mathrm{~K})$.

2.8. Equilibrium Adsorption Studies. All conducted adsorption experiments were performed as duplicates and an average reading was taken. The batch adsorption experiments were conducted in a set of $100 \mathrm{~mL}$ Erlenmeyer flasks containing $0.05 \mathrm{~g}$ adsorbent and $50 \mathrm{~mL}$ dye solutions with various initial concentrations (10, 20, 30, 40, and $50 \mathrm{mg} / \mathrm{L})$. The flasks were agitated in thermostated shaker bath/GFL (D-3006), at 70 cycles/min and $25^{\circ} \mathrm{C}$ until the equilibrium was reached. Dye concentrations in the supernatant solutions were measured using a UV-Vis spectrophotometer. Dyes uptake at equilibrium, $q_{e}(\mathrm{mg} / \mathrm{g})$, was determined by

$$
q_{e}=\frac{\left(C_{o}-C_{e}\right) V}{W}
$$

where $C_{o}$ and $C_{e}(\mathrm{mg} / \mathrm{L})$ are the initial and equilibrium concentrations of the dye solutions, respectively. $V(\mathrm{~L})$ is the 

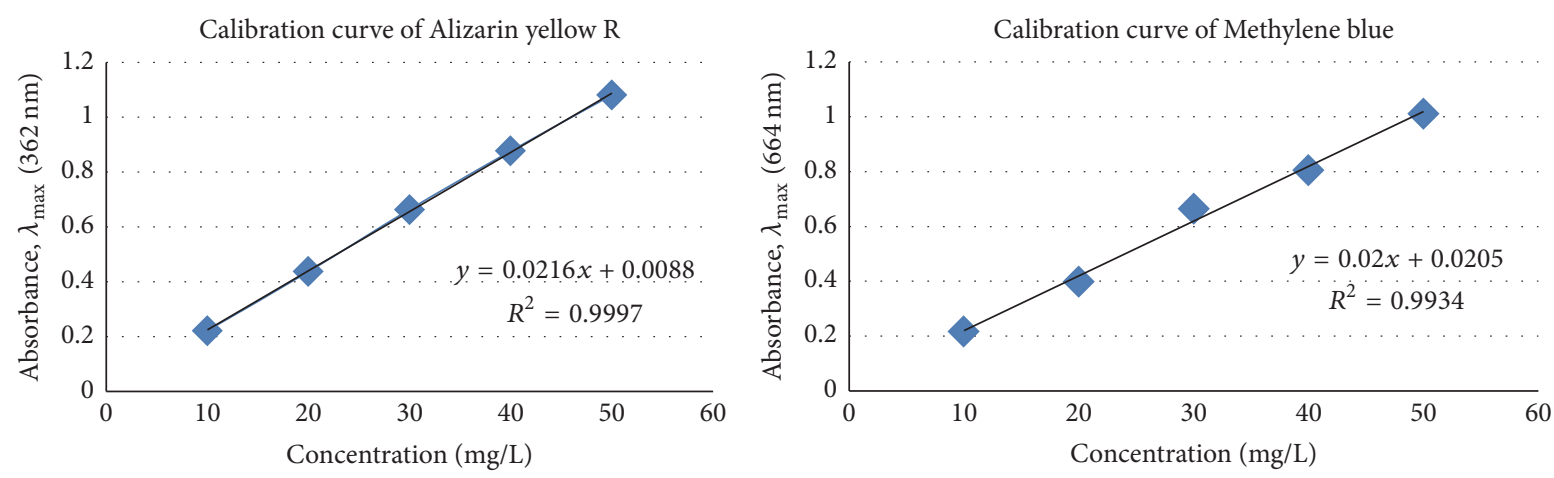

Figure 1: Calibration curves of Alizarin yellow and Methylene blue at different concentrations (10-50) mg/L.

volume of the solution, and $W(\mathrm{~g})$ is the mass of adsorbent used. Langmuir and Freundlich adsorption isotherms were used to describe the equilibrium characteristics of adsorption. from

Also percentage of removal $(\% R)$ of dyes was calculated

$$
\% R=\frac{C_{o}-C_{e}}{C_{o}} \times 100
$$

2.9. Langmuir Isotherm. It is the most widely used equation that is valid for monolayer adsorption, and the equation is given by [21]

$$
\frac{C_{e}}{q_{e}}=\frac{C_{e}}{q_{\max }}+\frac{K_{L}}{q_{\max }}
$$

where $q_{\max }$ is the maximum adsorption capacity at monolayer in $\left(\mathrm{mg} \mathrm{g}^{-1}\right), C_{e}$ is the concentration of dyes at equilibrium, $q_{e}$ is the adsorption capacity at equilibrium $\left(\mathrm{mg} \mathrm{g}^{-1}\right)$, and $K_{L}$ is the Langmuir constant representing the affinity of binding sites (L/mg). A linear plot of $C_{e} / q_{e}$ versus $C_{e}$ gives $q_{\max }$ and $K_{L}$.

One of the essential characteristics of the Langmuir isotherm is a dimensionless constant of separation factor or equilibrium parameter, $R_{L}$, which is given by

$$
R_{L}=\frac{1}{1+K_{L} C_{o}},
$$

where $K_{L}$ is the Langmuir constant and $C_{o}$ is the initial concentration of dyes. If $R_{L}$ values are between 0 and 1 then it indicates favorable adsorption, while $R_{L}>1, R_{L}=1$, and $R_{L}=0$ indicate unfavorable, linear, and irreversible adsorption isotherms.

2.10. Freundlich Isotherm. Another widely used isotherm is the empirical Freundlich equation which is based on sorption on a heterogeneous surface. The heat of adsorption decreases in value with an increase in the extent of adsorption. If the decrease in the heat of adsorption is logarithmic, then it will indicate that the adsorption sites are distributed exponentially with respect to the adsorption energy which is different between the groups of adsorption sites. The Freundlich equation is known as [22]

$$
q_{e}=K_{F} C_{e}^{1 / n} \text {. }
$$

So, the linear form of the Freundlich isotherm is

$$
\log q_{e}=\log K_{F}+\frac{1}{n} \log C_{e},
$$

where $K_{F}$ and $n$ are the Freundlich constants representing sorption capacity $\left(\mathrm{mg} \mathrm{g}^{-1}\right)$ and intensity, respectively. $K_{F}$ and $n$ can be determined from $\operatorname{linear}$ plot of $\log q_{e}$ against $\log C_{e}$.

2.11. Thermodynamic Modeling. The thermodynamic parameters include Gibbs free energy change $(\Delta G)$, enthalpy change $(\Delta H)$, and entropy change $(\Delta S)$ involved in an adsorption system. The values of $\Delta H, \Delta G$, and $\Delta S$ were calculated from the following equations:

$$
\begin{aligned}
K_{D} & =\frac{q_{e}}{C_{e}}, \\
\Delta G & =-R T \ln K_{D}, \\
\ln K_{D} & =\frac{\Delta S}{R}-\frac{\Delta H}{R T},
\end{aligned}
$$

where $R\left(8.314 \mathrm{JK}^{-1} \mathrm{~mol}^{-1}\right)$ is the universal gas constant and $T(\mathrm{~K})$ is the absolute solution temperature. The values of $\Delta H$ and $\Delta S$ were determined from the slope and intercept of the Van't Hoff plot of $\ln K_{D}$ versus $1 / T$.

2.12. Kinetic Studies. The kinetic studies were carried out by agitation of $50 \mathrm{~mL}$ solutions of each dye with initial concentrations $10-40 \mathrm{mg} / \mathrm{L}$ and $0.05 \mathrm{~g}$ of each adsorbent, at room temperature and at different time intervals from 10 to $60 \mathrm{~min}$. These kinetic experiments were analyzed using pseudo-firstorder [23] and pseudo-second-order equations [24].

2.13. Pseudo-First-Order Equation. This equation of Lagergren is given by

$$
\frac{d q_{t}}{d t}=K_{1}\left(q_{e}-q_{t}\right)
$$


where $q_{t}(\mathrm{mg} / \mathrm{g})$ is the adsorption capacity at time $t$ and $K_{1}$ is the rate constant of the adsorption process $\left(\mathrm{min}^{-1}\right)$. The integrated form of the first-order equation is given as follows:

$$
\log \left(q_{e}-q_{t}\right)=\log \left(q_{e}\right)-\frac{K_{1}}{2.303} t .
$$

2.14. Pseudo-Second-Order Equation. This model assumes that the rate limiting step is chemisorption in nature. The mechanism may involve valence forces by sharing or through the exchange of electrons between adsorbent and adsorbate. This kinetic equation is given as follows:

$$
\frac{d q_{t}}{d t}=K_{2}\left(q_{e}-q_{t}\right)^{2}
$$

where $K_{2}\left(\mathrm{~g} \mathrm{mg}^{-1} \mathrm{~min}^{-1}\right)$ is the second-order rate constant of the adsorption process. The linearized form of the secondorder equation is obtained by integrating (10) to give

$$
\frac{t}{q_{t}}=\frac{1}{K_{2 q_{e}^{2}}}+\frac{1}{q_{e}} t
$$

2.15. Intraparticle Diffusion Study. The rate constant of intraparticle diffusion $K_{\text {diff }}$ was calculated by using the following equation [25]:

$$
q_{t}=K_{\mathrm{diff}} t^{1 / 2}+C
$$

where $q_{t}(\mathrm{mg} / \mathrm{g})$ is the amount adsorbed at time $t$ and $t^{1 / 2}$ is the square root of the time $\left(\mathrm{min}^{1 / 2}\right)$. It is an empirical relationship that is common to most adsorption processes, where uptake varies almost proportionally with $t^{1 / 2}$ rather than with the contact time. The values of $K_{\text {diff }}\left(\mathrm{mg} / \mathrm{g} \cdot \mathrm{min}^{1 / 2}\right)$ and $C(\mathrm{mg} / \mathrm{g})$ were calculated from slope of the curves from plotting $q_{t}$ versus $t^{1 / 2}$.

2.16. Determination of Activation Energy. The activation energy, $E_{a}$, can be obtained by using the Arrhenius equation [26] as follows:

$$
\ln K=\ln A-\frac{E_{a}}{R T}
$$

where $A$ is the frequency factor $\left(\mathrm{min}^{-1}\right), K$ is the rate constant value for the adsorption process, and $E_{a}$ is the activation energy in $\mathrm{KJ} \mathrm{mol}^{-1}$. $E_{a}$ can be calculated from the slope of the graph $\ln K$ versus $1 / T$. The low activation energy indicates that the adsorption process is a physical adsorption.

2.17. Desorption Studies. After adsorption of the dyes, the adsorbent was separated by centrifugation and the residual solid was dried at $40^{\circ} \mathrm{C}$. The obtained solid was added to $6 \mathrm{~mL}$ of $0.1 \mathrm{M} \mathrm{NaOH}$ for $(\mathrm{AY})$ and $0.1 \mathrm{M} \mathrm{HCl}$ for $(\mathrm{MB})$ as back extractants. Samples were collected after 5, 10, 30, 60, and 90 min contact times with these extractants to evaluate dye recovery by means of UV-Vis spectrophotometer. The dye recovery was calculated by (14). The adsorption-desorption

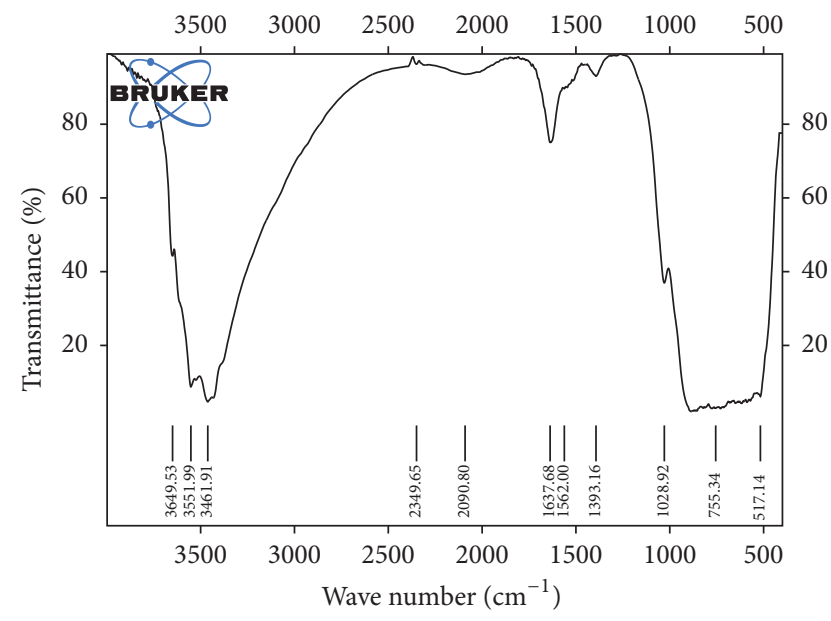

FIGURE 2: FTIR spectrum of $\gamma$-alumina nanoparticles.

cycle was repeated three times with the use of $50 \mathrm{mg} / \mathrm{L}$ for each dye solution.

$$
\text { Recovery }(\%)=\frac{\text { amount of desorbed metals }}{\text { amount of adsorbed metals }} \times 100 \text {. }
$$

2.18. Statistical Analysis. The data analysis was carried out by employing the regression correlation coefficient $\left(R^{2}\right)$, standard error (Std error) and standard deviation (Std deviation) that were calculated by Microsoft Excel 2007 program. Another important test is the Chi-square statistic test which is basically the sum of the squares of the differences between the experimental data and the theoretical data from each model. It is given by the following equation [27]:

$$
\chi^{2}=\sum_{i=1}^{i=N} \frac{\left(q_{e(\exp )}-q_{e(\mathrm{cal})}\right)^{2}}{q_{e(\mathrm{cal})}},
$$

where $q_{e(\exp )}$ is the equilibrium capacity $(\mathrm{mg} / \mathrm{g})$ from the experimental data and $q_{e(\mathrm{cal})}(\mathrm{mg} / \mathrm{g})$ is the equilibrium capacity obtained by calculation from the model. If the experimental data and the data from the model were similar, the value of $\chi^{2}$ would be small and vice versa. Also, lower values of standard error and standard deviation give better indication of the most suitable model.

\section{Results and Discussion}

3.1. Characterization. The FTIR spectra of $\gamma$-alumina and its modified form (DNPH- $\gamma$-alumina) are shown in Figures 2 and 3. The FTIR spectrum of $\gamma$-alumina showed a broad band at $3551-3461 \mathrm{~cm}^{-1}$ attributed to the $-\mathrm{OH}$ stretching vibrations related to the lattice of water molecules; this may indicate the presence of moisture in the powder of $\mathrm{KBr}$ [14], also a weak band at $1637 \mathrm{~cm}^{-1}$ associated with $\mathrm{Al}-\mathrm{OH}$ bond stretching vibrations, a weak band due to Al-O bond vibration at $1332 \mathrm{~cm}^{-1}$, symmetric stretching vibration Al-O$\mathrm{Al}$ at $755 \mathrm{~cm}^{-1}$, and $517 \mathrm{~cm}^{-1}$ attributed to the bending vibrations of $\mathrm{Al}-\mathrm{O}-\mathrm{Al}$ bonds. The same observations have been 


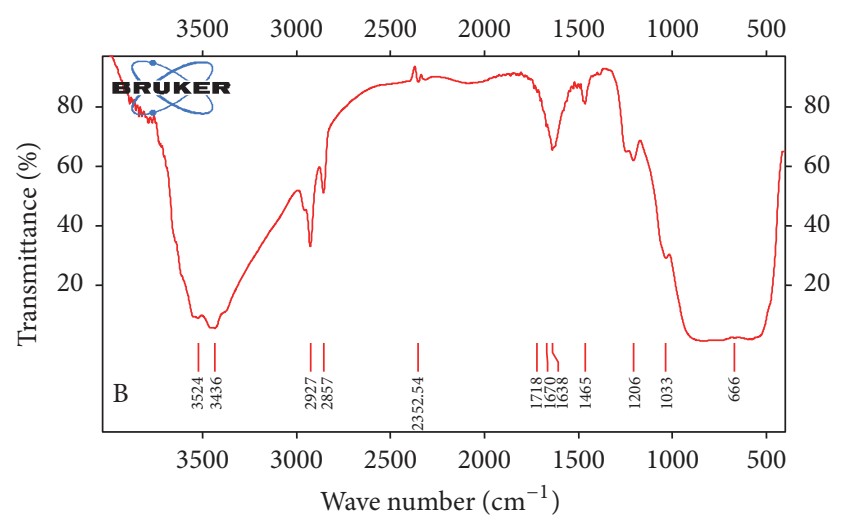

FIGURE 3: FTIR spectrum of DNPH- $\gamma$-alumina.

TABLE 1: Surface characteristics of $\gamma$-alumina and DNPH- $\gamma$ alumina.

\begin{tabular}{lcc}
\hline Surface properties & $\gamma$-Alumina & DNPH- $\gamma$-alumina \\
\hline BET surface area & $169.643 \mathrm{~m}^{2} / \mathrm{g}$ & $117.217 \mathrm{~m}^{2} / \mathrm{g}$ \\
\hline BJH adsorption surface area & $200.681 \mathrm{~m}^{2} / \mathrm{g}$ & $162.102 \mathrm{~m}^{2} / \mathrm{g}$ \\
Pore volume & $0.288 \mathrm{cc} / \mathrm{g}$ & $0.226 \mathrm{cc} / \mathrm{g}$ \\
Pore diameter & $1.192 \mathrm{~nm}$ & $1.217 \mathrm{~nm}$ \\
\hline BJH desorption surface area & $176.592 \mathrm{~m}^{2} / \mathrm{g}$ & $152.771 \mathrm{~m}^{2} / \mathrm{g}$ \\
Pore volume & $0.281 \mathrm{cc} / \mathrm{g}$ & $0.223 \mathrm{cc} / \mathrm{g}$ \\
Pore diameter & $1.415 \mathrm{~nm}$ & $1.397 \mathrm{~nm}$ \\
\hline $\mathrm{pH}_{\mathrm{zpc}}$ & 8.5 & 6 \\
\hline
\end{tabular}

obtained for $\gamma$-alumina in other studies $[10,14,18]$. DNPH$\gamma$-alumina FTIR spectrum showed a more broad band due to stretching vibrations of $\mathrm{N}-\mathrm{H}$ with varying degrees of $\mathrm{H}$ bonding at $3600-3300 \mathrm{~cm}^{-1}, \mathrm{NH}_{2}$ scissoring vibration at $1670 \mathrm{~cm}^{-1}$, Al-OH stretching vibrations at $1638 \mathrm{~cm}^{-1}, \mathrm{C}-$ $\mathrm{NO}_{2}$ bond at $1465 \mathrm{~cm}^{-1}$ and 2927 and $2857 \mathrm{~cm}^{-1}$ assigned to aliphatic $-\mathrm{CH}_{3}$ and $-\mathrm{CH}_{2}$ related to the alkyl group in sodium dodecyl sulfate, $\mathrm{S}=\mathrm{O}$ symmetric and antisymmetric stretch of SDS at 1206 and $1034 \mathrm{~cm}^{-1}$, respectively, and in plane and out of plane bending of C-H, C-C-C, and C- $\mathrm{NO}_{2}$ bonds that overlap between 900 and $500 \mathrm{~cm}^{-1}$. This is in agreement with DNPH- $\gamma$-alumina prepared by Afkhami et al. [18]. BET and $\mathrm{BJH}$ measurements for the surface areas of $\gamma$-alumina and DNPH- $\gamma$-alumina are shown in Table 1; the surface areas for the adsorbents are relatively high but there is a decrease in all these parameters for the modified DNPH- $\gamma$-alumina and this may be contributed to large size of the organic ligand which blocks the surface of $\gamma$-alumina [28].

The SEM and TEM of the adsorbents are given in Figures 4 and 5, respectively; they show the surface and textural morphology. As shown in these figures the $\gamma$-alumina is spherical in shape and has a mean diameter of 10-50 nm. The modified DNPH- $\gamma$-alumina had a mean diameter in the range between 30 and $70 \mathrm{~nm}$. This change in the shape and size of the particles shown in the SEM figures, in addition to FTIR analysis, indicates that the alumina nanoparticles have been coated with SDS and immobilization of DNPH in the coated SDS- $\gamma$-alumina has occurred. This coating process has resulted in the agglomeration and the change in the particle size of adsorbent [29]. The figures agree with that obtained by Afkhami et al. [18]. The X-ray diffraction analysis given in Figure 6 confirms the nanocrystalline structure of $\gamma$-alumina.

3.2. Effect of $p H$ and Point of Zero Charge Determination. The point of zero charge $\mathrm{pH}_{\mathrm{zpc}}$ has been obtained and was found to be 8.5 for $\gamma$-alumina and approximately 6 for $\mathrm{DNPH}-\gamma$-alumina, as shown in Figure 7. The $\mathrm{pH}_{\mathrm{zpc}}$ for $\gamma$ alumina obtained agrees with other studies in which the $\mathrm{pH}_{\mathrm{zpc}}$ was 7.9 [20] and 8.0 [10], while the effect of $\mathrm{pH}$ on the removal of $\mathrm{AY}$ and $\mathrm{MB}$ is given in Figure 8. The $\mathrm{pH}$ factor is important in controlling the adsorption process especially for dyes adsorption. The removal of Methylene blue (MB) on the adsorbents was found favorable at ( $\mathrm{pH} 11)$ while Alizarin yellow removal was optimized at $\mathrm{pH}$ 4. The same observation was found in other studies for removal of $\mathrm{MB}$ and other cationic dyes [30-32]. Also, similar observations were found for AY [33] or other anionic dyes such as Congo red [32] and acid orange-7 [10]. In general, at solution $\mathrm{pH}$ above $\mathrm{pH}_{\mathrm{zpc}}$, the negative charge density of the surface of adsorbent will increase and favors the adsorption of cationic dyes due to electrostatic interactions [30], while at $\mathrm{pH}$ values lower than $\mathrm{pH}_{\mathrm{zpc}}$, acidic $\mathrm{pH}$, the surface of the adsorbents is surrounded by hydronium ions $\mathrm{H}^{+}$which are favorably replaced by Alizarin yellow dye. So, as $\mathrm{pH}$ decreases, the net positive surface potential is greater for removal of anionic dyes due to electrostatic interactions [33].

3.3. Effect of Amount of Adsorbent. Usually, the removal of dyes increases with increasing adsorbent dose, as the number of sorption sites at the surface will increase when the dose of the adsorbent is increased. So, it will increase the percentage of dye removal from the solution. The effect of adsorbent dose shows the effectiveness of the adsorbent and also the ability of dyes to be adsorbed with a minimum amount of adsorbent dosage, in order to verify the ability of an adsorbent from an economical point of view [1]. Figure 9 shows that $0.05 \mathrm{~g}$ of each adsorbent is efficient for the removal of $\mathrm{MB}$ and $\mathrm{AY}$.

3.4. Effect of Contact Time. The rate of dye removal is high initially, due to high concentration gradient and more available adsorption sites, until the adsorption process reaches equilibrium where no further uptake of adsorbate by adsorbent will occur as time proceeds [34]. The results show that equilibrium was obtained after 60 minutes of agitation time as shown in Figure 10.

3.5. Adsorption Isotherms. Parameters that are obtained from the equilibrium models can give useful information on the sorption mechanism, surface properties, and the affinity for an adsorbent [35]. The linear plots of these isotherms are shown in Figures 11 and 12. The adsorption isotherm parameters and their statistical comparisons are listed in Table 2. From the statistical analysis it is clear that the Langmuir isotherm fits superiorly on the adsorption of AY on $\gamma$-alumina and DNPH- $\gamma$-alumina with a maximum adsorption capacity of $37.7 \mathrm{mg} / \mathrm{g}$ and $47.8 \mathrm{mg} / \mathrm{g}$ on $\gamma$-alumina 


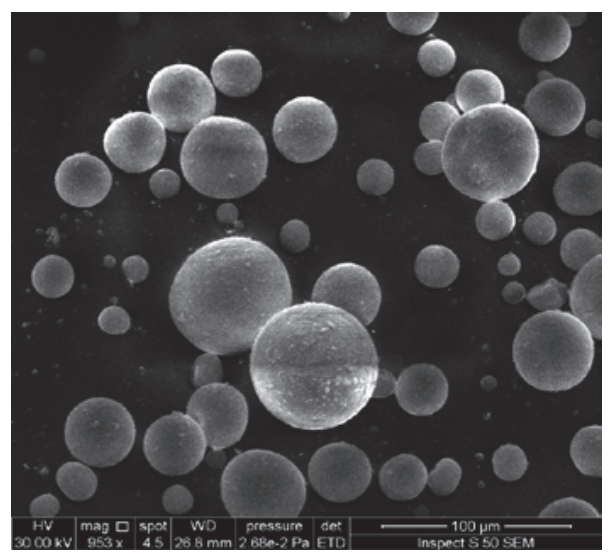

(a)

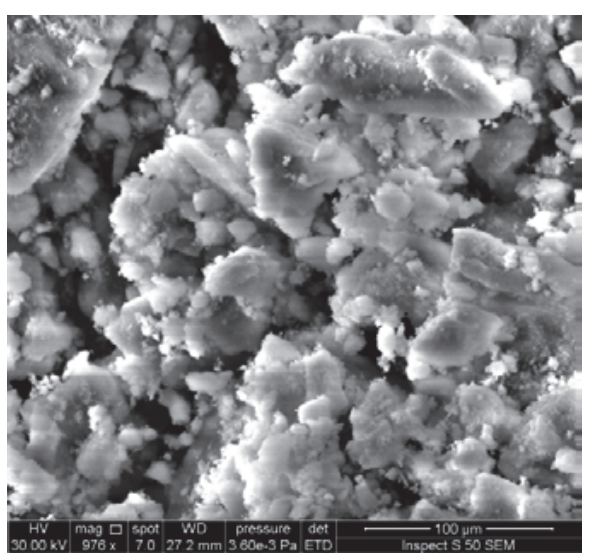

(b)

FIGURE 4: SEM images of (a) $\gamma$-alumina and (b) DNPH- $\gamma$-alumina.

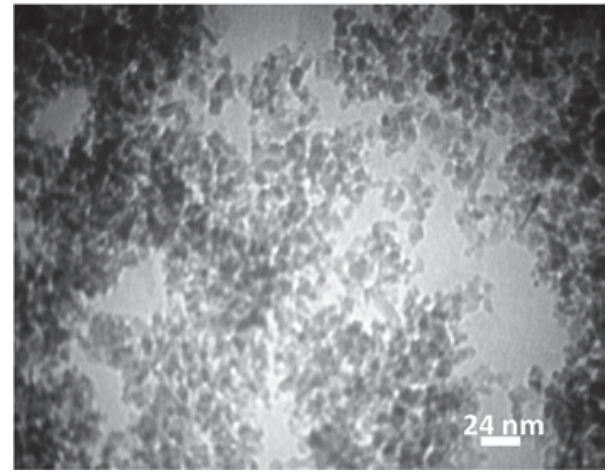

(a)

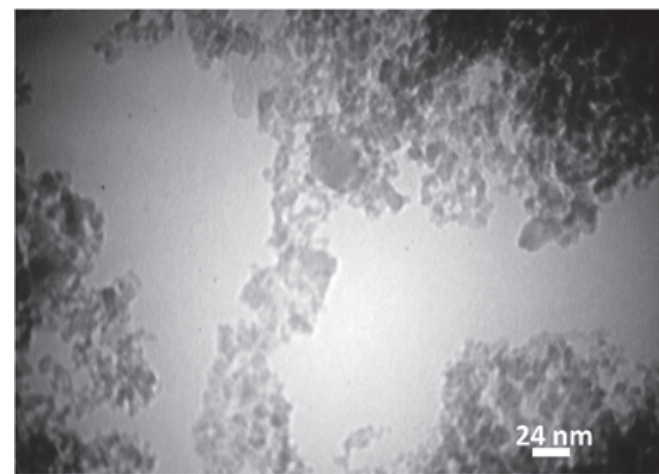

(b)

Figure 5: TEM images of (a) $\gamma$-alumina and (b) DNPH- $\gamma$-alumina.

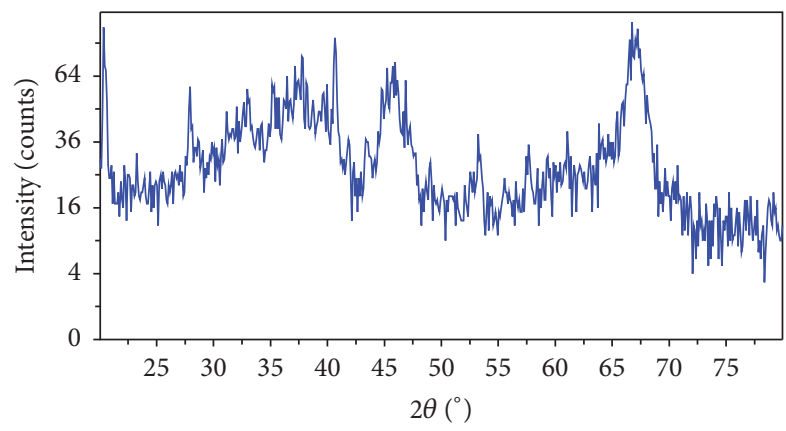

FIGURE 6: X-ray diffractogram of nanocrystalline $\gamma$-alumina.

and DNPH- $\gamma$-alumina, respectively. The favorable Langmuir isotherm is also tested further from its $R_{L}$ which is favorable when $0<R_{L}<1$ as in the case for AY adsorption on $\gamma$-alumina and DNPH- $\gamma$-alumina. The Langmuir isotherms basic assumption is that the adsorption takes place at specific homogeneous sites, so once a dye occupies this site no further adsorption can take place at this site [30]. On the basis of the statistical analysis for the adsorption of $\mathrm{MB}$ on $\gamma$-alumina

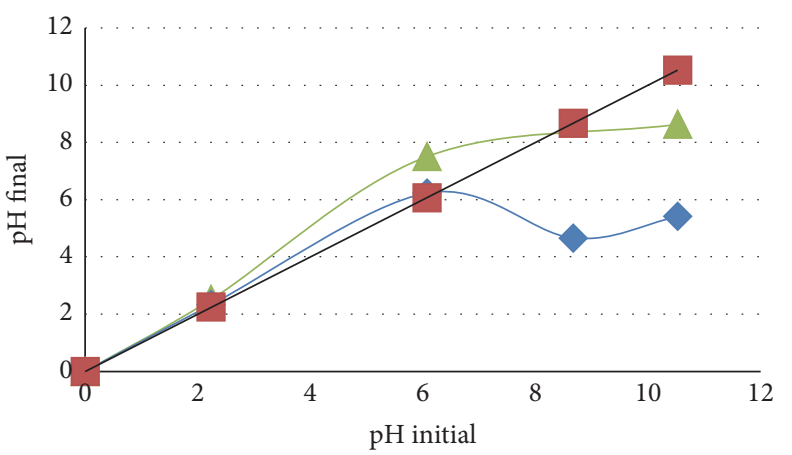

Without adsorbent
- With nanoalumina
- With DNPH-nanoalumina

Figure 7: Determination of $\mathrm{pH}_{\mathrm{zpc}}$.

it is clear that Freundlich isotherm fits the process best, which is applied to the nonideal adsorptions that occur on heterogeneous surfaces and as multilayer adsorption [36]. As for the adsorption of $\mathrm{MB}$ on $\mathrm{DNPH}-\gamma$-alumina it showed 

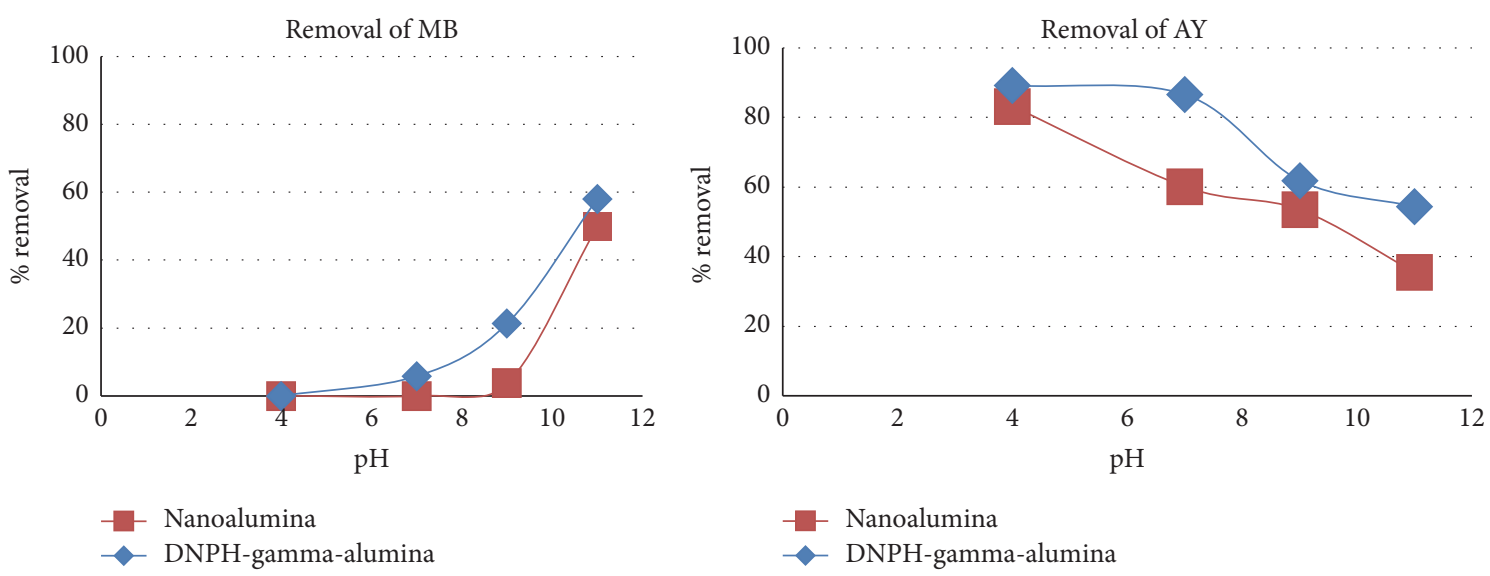

FIGURE 8: Effect of $\mathrm{pH}$ on the removal of the dyes, $50 \mathrm{mg} / \mathrm{L}$ of dye concentration, $90 \mathrm{~min}, 0.1 \mathrm{~g}$ adsorbent amounts, and $298 \mathrm{~K}$.

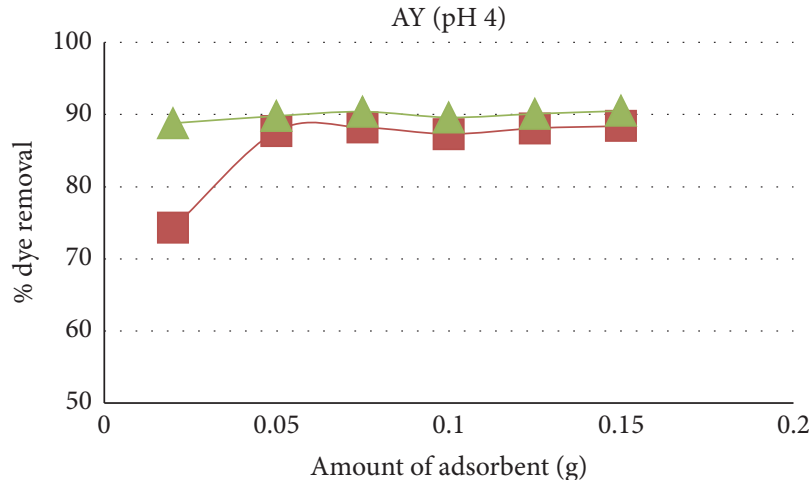

Nanoalumina

DNPH-nanoalumina

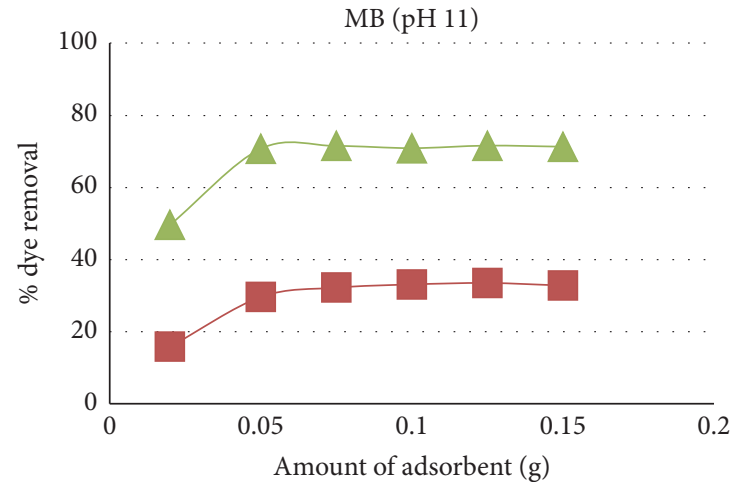

Nanoalumina

- DNPH-nanoalumina

FIGURE 9: The effect of amount of adsorbent on the removal of the dyes, $50 \mathrm{mg} / \mathrm{L}$ dye concentration, $90 \mathrm{~min}$, and $298 \mathrm{~K}$.
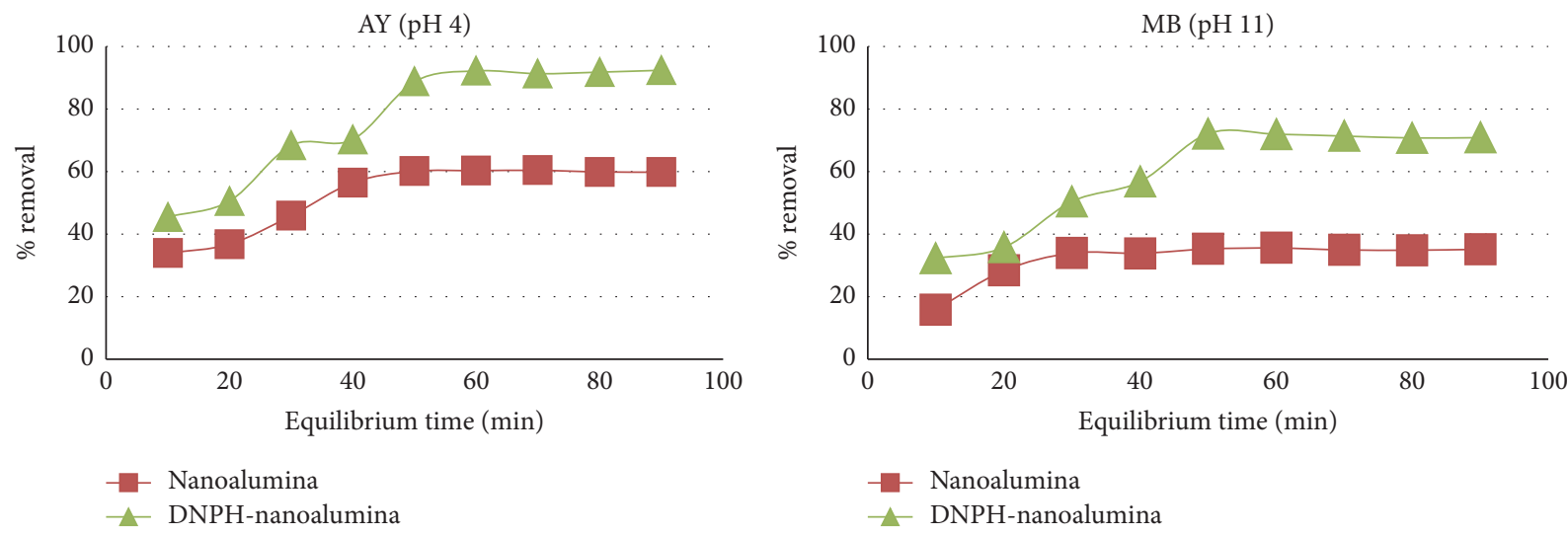

FIGURE 10: Equilibrium time for the removal of dyes, $50 \mathrm{mg} / \mathrm{L}$ dye concentration, $298 \mathrm{~K}$, and $0.05 \mathrm{~g}$ adsorbent.

preference of the Langmuir isotherm with a maximum adsorption capacity of $32.8 \mathrm{mg} / \mathrm{g}$.

3.6. Kinetic Studies. The kinetic plots of the pseudo-first and second-order kinetic equations are shown in Figures 13 and 14 and the constants with the statistical analysis of the kinetic models are listed in Table 3. The agreement between experimental and calculated values of $q_{e}$ with the corresponding correlation coefficients $\left(R^{2}\right)$ for the secondorder equation is greater than that of the first-order model, and the smaller $\chi^{2}$ values for the second-order model result in better applicability of the pseudo-second-order model 


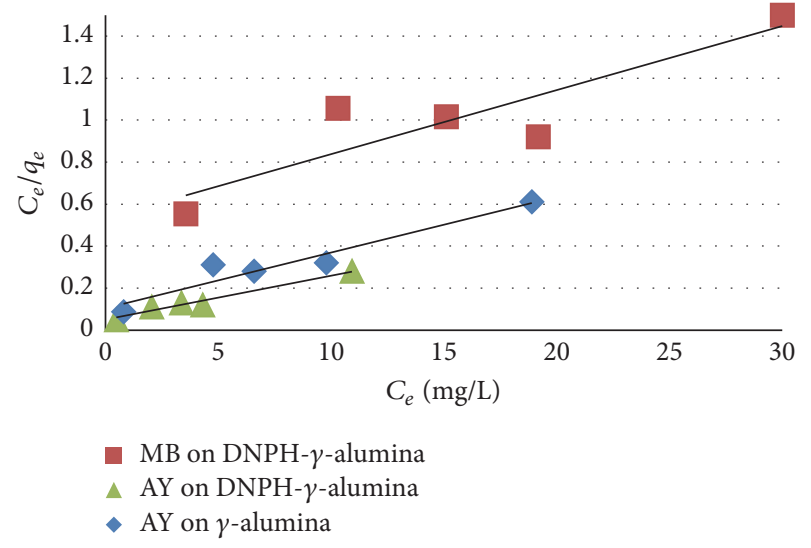

FIGURE 11: Langmuir isotherm plots for adsorption of AY and MB on $\gamma$-alumina and DNPH- $\gamma$-alumina.

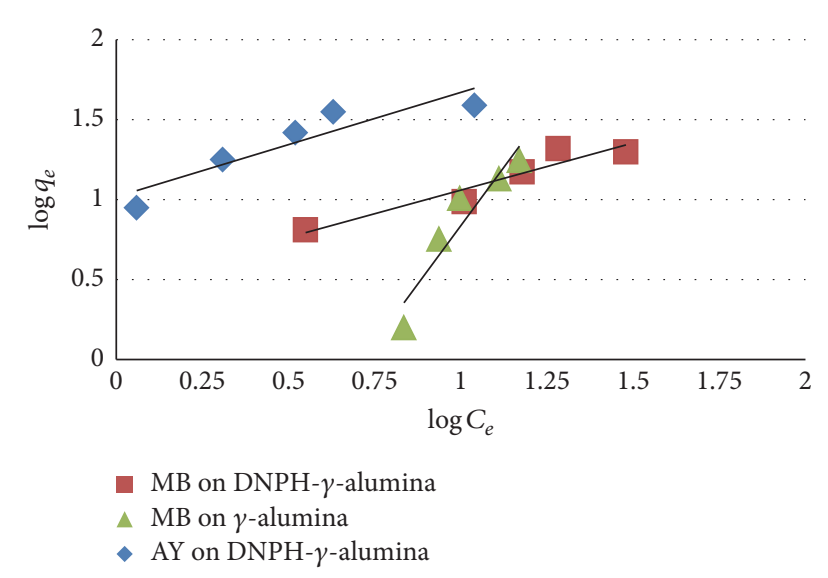

Figure 12: Freundlich isotherm plots for adsorption of AY an MB on $\gamma$-alumina and DNPH- $\gamma$-alumina.

to describe the adsorption process [37], indicating that the process is controlled by chemisorption [38].

Intraparticle diffusion model is commonly used for identifying the mechanism that is involved in the sorption process. An overall adsorption process of a solute onto the solid surface may be controlled by one or more steps, for example, boundary layer (film), external diffusion, pore diffusion, or combination of several steps. Table 3 gives the intraparticle diffusion parameters for the adsorption process of $\mathrm{AY}$ and $\mathrm{MB}$ on $\gamma$-alumina and DNPH- $\gamma$-alumina. The $K_{\text {diff }}$ (the intraparticle diffusion rate constant and $C$ gives an indication of the thickness of the boundary layer), and since the intraparticle curve did not pass through the origin shown in Figures 15 and 16, this model is poorer than another model (pseudo second-order model) to fit the kinetics of the adsorption process. From Table 3, it is observed that the adsorption of dye follows more closely pseudo-secondorder kinetics. Therefore, it can be concluded that the pseudosecond-order model is better in describing the kinetics of adsorption of $\mathrm{AY}$ and $\mathrm{MB}$.

Similar results have been seen in another study [10].
TABLE 2: Adsorption isotherms and their statistical comparison values.

\begin{tabular}{|c|c|c|c|c|}
\hline \multirow{2}{*}{ Dye } & \multirow{2}{*}{$\begin{array}{l}\text { Isotherm } \\
\text { model }\end{array}$} & \multirow{2}{*}{$\begin{array}{l}\text { Isotherm } \\
\text { parameters }\end{array}$} & \multicolumn{2}{|c|}{ Adsorbents } \\
\hline & & & $\gamma$-Alumina & DNPH- $\gamma$-alumina \\
\hline \multirow{7}{*}{ AY } & \multirow{7}{*}{ Langmuir } & $q_{\max }(\mathrm{mg} / \mathrm{g})$ & 37.7 & 47.8 \\
\hline & & $K_{L}(\mathrm{~L} / \mathrm{mg})$ & 3.97 & 2.37 \\
\hline & & $R_{L}$ & 0.005 & 0.008 \\
\hline & & $R^{2}$ & 0.931 & 0.969 \\
\hline & & Std error & 0.057 & 0.017 \\
\hline & & Std deviation & 0.19 & 0.08 \\
\hline & & $\chi^{2}$ & 3.5 & 1.6 \\
\hline \multirow{6}{*}{ AY } & \multirow{6}{*}{ Freundlich } & $1 / n$ & 0.41 & 0.65 \\
\hline & & $K_{F}(\mathrm{mg} / \mathrm{g})$ & 9.80 & 10.41 \\
\hline & & $R^{2}$ & 0.940 & 0.845 \\
\hline & & Std error & 0.075 & 0.118 \\
\hline & & Std deviation & 0.22 & 0.26 \\
\hline & & $\chi^{2}$ & 27.4 & 79.2 \\
\hline \multirow{7}{*}{ MB } & \multirow{7}{*}{ Langmuir } & $q_{\max }(\mathrm{mg} / \mathrm{g})$ & -2.86 & 32.8 \\
\hline & & $K_{L}(\mathrm{~L} / \mathrm{mg})$ & -0.064 & 17.4 \\
\hline & & $R_{L}$ & -0.45 & 0.001 \\
\hline & & $R^{2}$ & 0.576 & 0.797 \\
\hline & & Std error & 1.112 & 0.176 \\
\hline & & Std deviation & 1.48 & 0.34 \\
\hline & & $\chi^{2}$ & -146.4 & 1.58 \\
\hline \multirow{6}{*}{$\mathrm{MB}$} & \multirow{6}{*}{ Freundlich } & $1 / n$ & 2.94 & 0.94 \\
\hline & & $K_{F}(\mathrm{mg} / \mathrm{g})$ & 0.008 & 1.20 \\
\hline & & $R^{2}$ & 0.892 & 0.985 \\
\hline & & Std error & 0.158 & 0.075 \\
\hline & & Std deviation & 0.42 & 0.22 \\
\hline & & $\chi^{2}$ & $38,684.8$ & 496.1 \\
\hline
\end{tabular}

3.7. Energy of Activation $E_{a}$. Energy of activation data has been obtained for the removal of $A Y$ and $M B$ and is given in Table 4. It can be seen that the adsorption of AY on $\gamma$-alumina has lower $E_{a}$ value, but the modification of $\gamma$-alumina may have changed the adsorption process to a chemisorption having higher $E_{a}$, especially at higher concentrations. The adsorption of MB on the modified- $\gamma$-alumina shows lower energy of activations.

3.8. Thermodynamic Parameters. The thermodynamic parameters for the removal of AY and MB on $\gamma$-alumina and DNPH- $\gamma$-alumina are given in Table 5. Negative values of $\Delta G$ and $\Delta H$ indicate that the removal process is spontaneous and exothermic in nature (the adsorption decreases with increasing temperature). It depends mainly on the movement of dye molecules for each dye class. So, increasing temperature may decrease the adsorptive forces between the dye molecules and the active sites on the adsorbent surface, therefore, resulting in decreasing adsorption capacity [1]. Negative $\Delta S$ values could be related to the formation of higher order adsorbed species on a surface (decrease in the randomness tendency at the interface 
TABLE 3: Comparison of the kinetic constants and statistical parameters for the adsorption of AY and MB on $\gamma$-alumina and DNPH- $\gamma$-alumina.

\begin{tabular}{|c|c|c|c|c|c|c|}
\hline \multirow{3}{*}{ Dye } & \multirow{3}{*}{ Kinetic model } & \multirow{3}{*}{ Kinetic and Statistical parameters } & \multicolumn{2}{|c|}{$\gamma$-Alumina } & \multicolumn{2}{|c|}{ DNPH- $\gamma$-alumina } \\
\hline & & & \multicolumn{4}{|c|}{ Initial concentration $C_{o}(\mathrm{mg} / \mathrm{L})$} \\
\hline & & & 20 & 40 & 20 & 40 \\
\hline \multirow{6}{*}{ AY } & \multirow{6}{*}{ Pseudo-first order } & $q_{e(\mathrm{cal})} \mathrm{mg} / \mathrm{g}$ & 5.10 & 12.08 & 4.75 & 16.23 \\
\hline & & $K_{1}\left(\min ^{-1}\right)$ & 0.035 & 0.013 & 0.038 & 0.033 \\
\hline & & $R^{2}$ & 0.977 & 0.803 & 0.998 & 0.861 \\
\hline & & Std error & 0.098 & 0.116 & 0.03 & 0.24 \\
\hline & & Std deviation & 0.569 & 0.227 & 0.60 & 0.57 \\
\hline & & $\chi^{2}$ & 37.23 & 37.20 & 36.68 & 23.33 \\
\hline \multirow{6}{*}{ AY } & \multirow{6}{*}{ Pseudo-second order } & $q_{e(\mathrm{cal})} \mathrm{mg} / \mathrm{g}$ & 18.90 & 28.01 & 18.08 & 35.59 \\
\hline & & $K_{2}\left(\mathrm{~g} \mathrm{mg}^{-1} \mathrm{~min}^{-1}\right)$ & 0.019 & 0.012 & 0.021 & 0.005 \\
\hline & & $R^{2}$ & 0.999 & 0.999 & 0.999 & 0.986 \\
\hline & & Std error & 0.024 & 0.015 & 0.02 & 0.06 \\
\hline & & Std deviation & 0.837 & 0.564 & 0.87 & 0.45 \\
\hline & & $\chi^{2}$ & 0.00002 & 0.991 & 0.0009 & 0.0003 \\
\hline \multirow{6}{*}{ AY } & \multirow{6}{*}{ Intraparticle diffusion } & $C(\mathrm{mg} / \mathrm{g})$ & 12.97 & 14.85 & 12.69 & 19.28 \\
\hline & & $K_{\text {diff }}\left(\mathrm{mg} / \mathrm{g} \cdot \min ^{1 / 2}\right)$ & 0.745 & 2.003 & 0.664 & 1.842 \\
\hline & & $R^{2}$ & 0.974 & 0.758 & 0.983 & 0.922 \\
\hline & & Std error & 0.232 & 2.150 & 0.155 & 0.950 \\
\hline & & Std deviation & 1.285 & 3.913 & 1.03 & 2.95 \\
\hline & & $\chi^{2}$ & 1.440 & 5.640 & 2.14 & 13.98 \\
\hline AY & & $q_{e(\exp )} \mathrm{mg} / \mathrm{g}$ & 18.88 & 33.28 & 17.95 & 35.69 \\
\hline \multirow{6}{*}{ MB } & \multirow{6}{*}{ Pseudo-first order } & $q_{e(\mathrm{cal})} \mathrm{mg} / \mathrm{g}$ & 2.29 & 0.50 & 4.02 & 19.75 \\
\hline & & $K_{1}\left(\min ^{-1}\right)$ & 0.021 & -0.026 & 0.069 & 0.072 \\
\hline & & $R^{2}$ & 0.168 & 0.616 & 0.882 & 0.992 \\
\hline & & Std error & 0.851 & 0.374 & 0.458 & 0.119 \\
\hline & & Std deviation & 0.808 & 0.523 & 1.16 & 1.15 \\
\hline & & $\chi^{2}$ & 4.99 & 340.08 & 8.11 & 0.06 \\
\hline \multirow{6}{*}{ MB } & \multirow{6}{*}{ Pseudo-second order } & $q_{e(\mathrm{cal})} \mathrm{mg} / \mathrm{g}$ & 5.67 & 13.53 & 10.09 & 24.94 \\
\hline & & $K_{2}\left(\mathrm{~g} \mathrm{mg}^{-1} \mathrm{~min}^{-1}\right)$ & -62.21 & -7.8 & 0.034 & 0.004 \\
\hline & & $R^{2}$ & 1 & 1 & 0.998 & 0.996 \\
\hline & & Std error & $3.16 \times 10^{-4}$ & $3.16 \times 10^{-4}$ & 0.074 & 0.045 \\
\hline & & Std deviation & 2.79 & 1.17 & 1.57 & 0.63 \\
\hline & & $\chi^{2}$ & 0 & $7.4 \times 10^{-6}$ & 0.013 & 0.677 \\
\hline \multirow{6}{*}{ MB } & \multirow{6}{*}{ Intraparticle diffusion } & $C(\mathrm{mg} / \mathrm{g})$ & 1.83 & 13.92 & 7.09 & 5.79 \\
\hline & & $K_{\text {diff }}\left(\mathrm{mg} / \mathrm{g} \cdot \min ^{1 / 2}\right)$ & 0.434 & -0.300 & 0.357 & 2.163 \\
\hline & & $R^{2}$ & 0.432 & 0.650 & 0.994 & 0.960 \\
\hline & & Std error & 0.880 & 0.390 & 0.048 & 0.780 \\
\hline & & Std deviation & 1.012 & 0.573 & 0.55 & 3.40 \\
\hline & & $\chi^{2}$ & 8.057 & 0.010 & 0.96 & 38.91 \\
\hline $\mathrm{MB}$ & & $q_{e(\exp )} \mathrm{mg} / \mathrm{g}$ & 5.67 & 13.54 & 9.73 & 20.83 \\
\hline
\end{tabular}

between dyes and adsorbents) [39]. So, the adsorption of AY on the DNPH- $\gamma$-alumina is more energetically favorable at lower temperatures, and decrease in randomness could be attributed to the chemical nature of the adsorption.

3.9. Desorption Studies. Regeneration of an adsorbent could make the treatment process more economical and more feasible. Desorption study helps to provide more information about the mechanism of dye adsorption and recycling of spent adsorbent and adsorbate. The recovery of the adsorbent could be obtained twice as shown in Table 6. If dyes can be desorbed using neutral $\mathrm{pH}$ water, this may prove that the attachment of dye molecules to the adsorbent is by weak bonds [30], but in this study AY was desorbed using $0.2 \mathrm{M}$ $\mathrm{NaOH}$ and $\mathrm{MB}$ was desorbed using $0.2 \mathrm{M} \mathrm{HCl} \mathrm{MB}$. Because there is a strong interaction between the dyes and DNPH- $\gamma$ alumina then desorption of dyes was very low especially for AY.

The adsorption of AY on $\gamma$-alumina occurs because when the solution $\mathrm{pH}$ is below the point of zero charge of alumina 


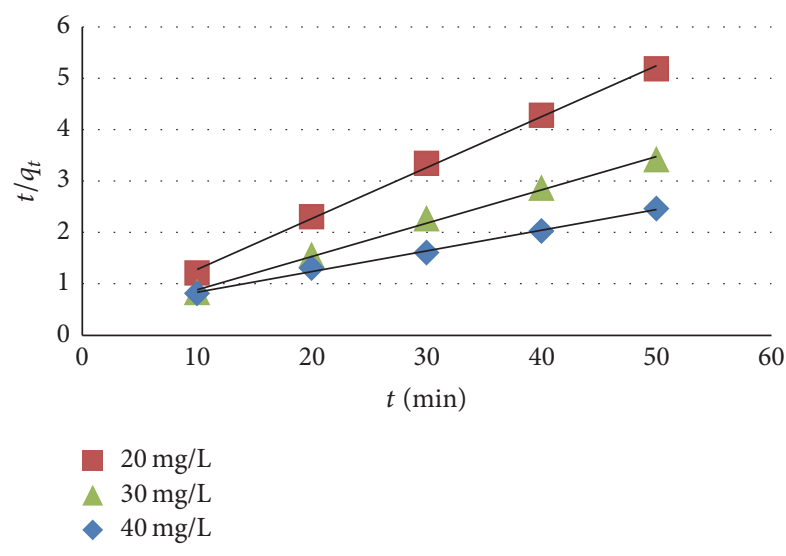

FIGURE 13: Pseudo-second-order kinetic plot for adsorption of MB on DNPH- $\gamma$-alumina nanoparticles at different initial concentrations.

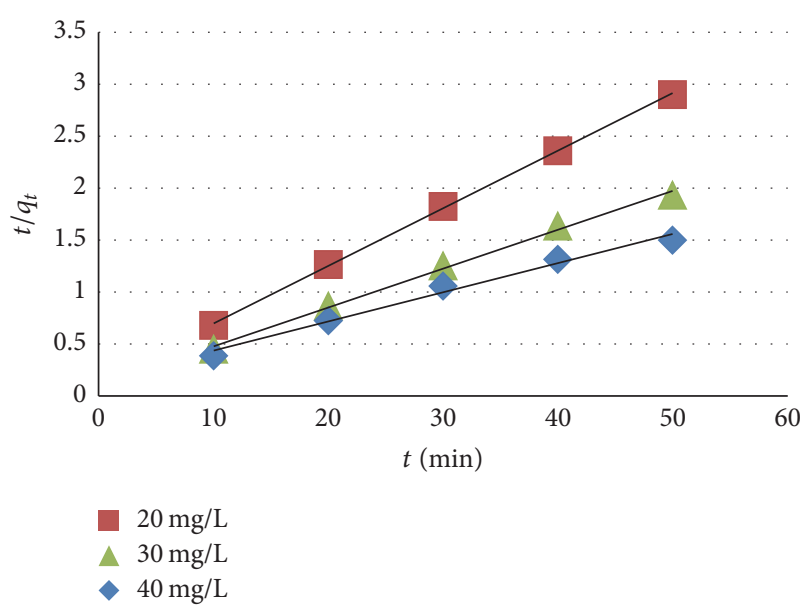

FIgURE 14: Pseudo-second-order kinetic plot for adsorption of AY on DNPH- $\gamma$-alumina nanoparticles at different initial concentrations.

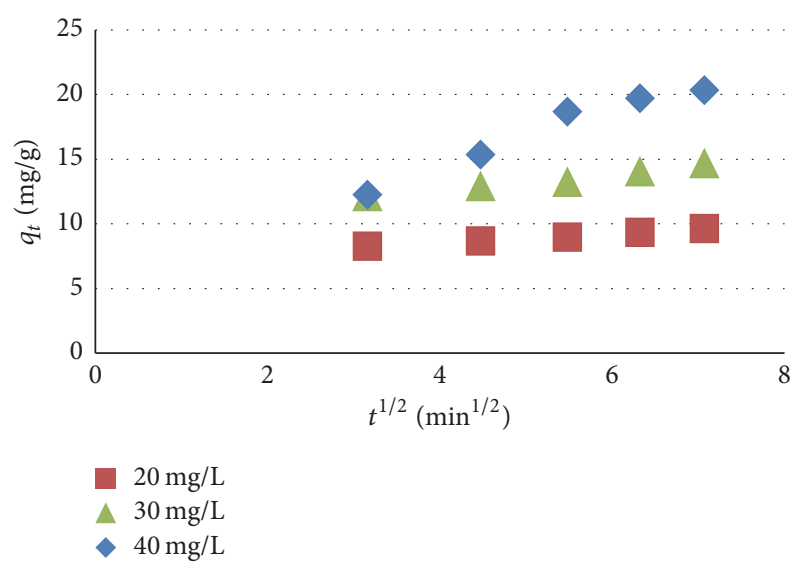

FIGURE 15: Intraparticle diffusion plot for adsorption of $\mathrm{MB}$ on $\mathrm{DNPH}-\gamma$-alumina nanoparticles at different initial concentrations.

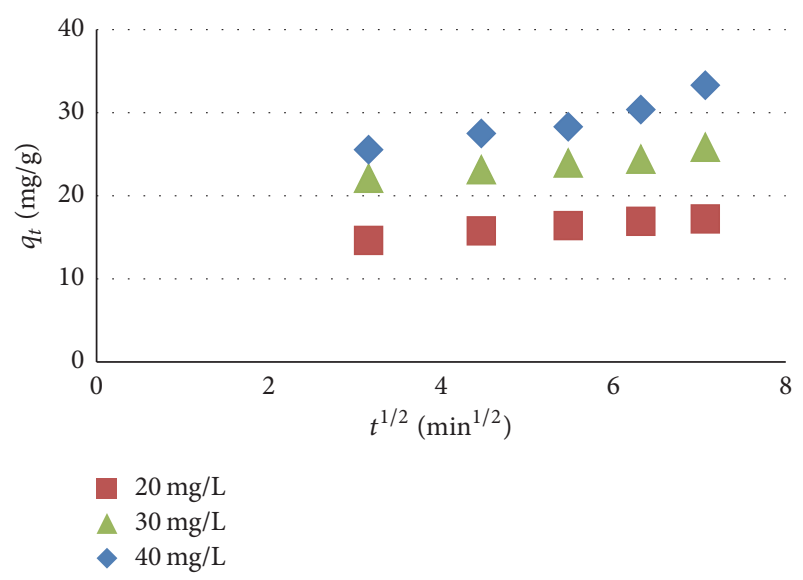

FIGURE 16: Intraparticle diffusion plot for adsorption of AY on DNPH- $\gamma$-alumina nanoparticles at different initial concentrations.

TABLE 4: Energy of activation for the adsorption of AY and $\mathrm{MB}$ on (1) $\gamma$-alumina and (2) DNPH- $\gamma$-alumina.

\begin{tabular}{lcccc}
\hline \multirow{2}{*}{ Dye } & \multirow{2}{*}{ Adsorbent } & \multicolumn{3}{c}{$E_{a}\left(\mathrm{KJmol}^{-1}\right)$} \\
& & $20 \mathrm{mg} / \mathrm{L}$ & $30 \mathrm{mg} / \mathrm{L}$ & $40 \mathrm{mg} / \mathrm{L}$ \\
\hline \multirow{2}{*}{$\mathrm{AY}$} & 1 & +36.3 & +37.5 & +47.2 \\
& 2 & +20 & +49.5 & +125.8 \\
$\mathrm{MB}$ & 1 & +5.5 & +20 & +21.7 \\
& 2 & +12.8 & +42.7 & +43.3 \\
\hline
\end{tabular}

TABLE 5: Thermodynamic parameters for the adsorption of AY and $\mathrm{MB}$ at different temperatures on (1) $\gamma$-alumina and (2) DNPH- $\gamma$ alumina.

\begin{tabular}{|c|c|c|c|c|c|c|c|c|}
\hline \multirow{2}{*}{\multicolumn{2}{|c|}{ Dye Sorbent }} & \multicolumn{5}{|c|}{$\Delta G \mathrm{KJ} / \mathrm{mol}$} & \multirow{2}{*}{$\begin{array}{c}\Delta H \\
\mathrm{KJ} / \mathrm{mol}\end{array}$} & \multirow{2}{*}{$\begin{array}{c}\Delta S \\
\mathrm{~J} / \mathrm{K} \cdot \mathrm{mol}\end{array}$} \\
\hline & & $293 \mathrm{~K}$ & $298 \mathrm{~K}$ & $308 \mathrm{~K}$ & $318 \mathrm{~K}$ & $328 \mathrm{~K}$ & & \\
\hline \multirow{2}{*}{ AY } & 1 & -1.2 & -1.0 & -0.9 & -0.7 & -0.6 & & \\
\hline & 2 & -5.4 & -5.2 & -5.3 & -5.2 & -5.2 & & -4.1 \\
\hline \multirow{2}{*}{ MB } & 1 & .4 & -0.1 & 5.6 & 19.6 & 14.1 & -12 & 415.9 \\
\hline & 2 & -0.3 & -0.2 & -0.1 & 0.4 & 1.1 & -11.0 & -36.4 \\
\hline
\end{tabular}

TABLE 6: Desorption of dyes from DNPH- $\gamma$-alumina.

\begin{tabular}{lcc}
\hline \multirow{2}{*}{ Adsorption } & \multicolumn{2}{c}{ Desorption (\% recovery) } \\
& AY $(50 \mathrm{mg} / \mathrm{L})$ & $\mathrm{MB}(50 \mathrm{mg} / \mathrm{L})$ \\
\hline 1st cycle & 17.29 & 83.4 \\
2nd cycle & 9.32 & 46.5 \\
\hline
\end{tabular}

which is $\mathrm{pH} 8.5$, the alumina surface will be positively charged and will interact with the negatively charged anionic dye (AY) by electrostatic interactions. The relatively low energy of activation $E_{a}$ for the adsorption of AY on $\gamma$-alumina may be further proof of this type of interaction.

SDS is coated on $\gamma$-alumina in acidic medium due to the same reason by the electrostatic interactions between the negative charged sulfate moiety of the SDS and the positively charged surface of $\gamma$-alumina forming hemimicelles and admicelles [40]; it does not increase the adsorption of AY which could be because both AY and the sulfate moiety 
of the SDS on $\gamma$-alumina are negatively charged in the acidic medium. When DNPH is immobilized by a chemical reaction it is trapped homogeneously in the hemimicelles and admicelles of the SDS- $\gamma$-alumina as explained by Afkhami et al. [18]. The adsorption of AY on the DNPH- $\gamma$-alumina surface increases due to the presence of DNPH; this could be attributed to the strong hydrophobic interactions between AY and DNPH and the increase in the energy of activation $\left(E_{a}\right)$ accompanying this process may be due to these hydrophobic interactions.

While the adsorption of MB on DNPH- $\gamma$-alumina also increases due to these hydrophobic interactions but to a lesser extent and this may be because of the steric-hindrance caused by the more bulky MB structure.

\section{Conclusions}

The modified immobilization of DNPH on SDS-coated $\gamma$ alumina has shown higher adsorption efficiency for the anionic dye (AY) which resulted in $95.6 \%$ removal opposed to $65.6 \%$ removal of the cationic dye $(\mathrm{MB})$. Different interactions have led to the increased adsorption of the dyes on $\mathrm{DNPH}-\gamma$-alumina including electrostatic and hydrophobic. Therefore, a modification process may increase the capability, effectiveness, and selectivity for the removal of certain pollutants by making them more selective, and the use of DNPH as a modifier could be used on a wider range of charged pollutants including metal ions and dyes.

\section{Competing Interests}

The authors declare that they have no competing interests.

\section{References}

[1] N. Sivarajasekar and R. Baskar, "Agriculture waste biomass valorization for cationic dyes sequestration: a concise review," Journal of Chemical and Pharmaceutical Research, vol. 7, no. 9, pp. 737-748, 2015.

[2] J. Carpenter, S. Sharma, A. K. Sharma, and S. Verma, "Adsorption of dye by using the solid waste from leather industry as an adsorbent," International Journal of Engineering Science Invention, vol. 2, no. 1, pp. 64-69, 2013.

[3] T. Robinson, G. McMullan, R. Marchant, and P. Nigam, "Remediation of dyes in textile effluent: a critical review on current treatment technologies with a proposed alternative," Bioresource Technology, vol. 77, no. 3, pp. 247-255, 2001.

[4] A. Srinivasan and T. Viraraghavan, "Decolorization of dye wastewaters by biosorbents: a review," Journal of Environmental Management, vol. 91, no. 10, pp. 1915-1929, 2010.

[5] T. Robinson, B. Chandran, and P. Nigam, "Removal of dyes from a synthetic textile dye effluent by biosorption on apple pomace and wheat straw," Water Research, vol. 36, no. 11, pp. 2824-2830, 2002.

[6] J.-F. Gao, Q. Zhang, K. Su, and J.-H. Wang, "Competitive biosorption of yellow $2 \mathrm{G}$ and reactive brilliant red $\mathrm{K}-2 \mathrm{G}$ onto inactive aerobic granules: simultaneous determination of two dyes by first-order derivative spectrophotometry and isotherm studies," Bioresource Technology, vol. 101, no. 15, pp. 5793-5801, 2010.
[7] N. Savage and M. S. Diallo, "Nanomaterials and water purification: opportunities and challenges," Journal of Nanoparticle Research, vol. 7, no. 4-5, pp. 331-342, 2005.

[8] A. Afkhami and R. Moosavi, "Adsorptive removal of Congo red, a carcinogenic textile dye, from aqueous solutions by maghemite nanoparticles," Journal of Hazardous Materials, vol. 174, no. 1-3, pp. 398-403, 2010.

[9] I. S. Al-Jobouri, S. A. Dhahir, and K. A. Al-Saade, "Adsorption study of Rhodamine $\mathrm{B}$ dye on Iraqi bentonite and modified bentonite by nanocompounds $\mathrm{TiO}_{2}, \mathrm{ZnO}, \mathrm{Al}_{2} \mathrm{O}_{3}$ and sodium dodecyl sulfate," American Journal of Environmental Sciences, vol. 9, no. 3, pp. 269-279, 2013.

[10] E. Khosla, S. Kaur, and P. N. Dave, "Mechanistic study of adsorption of acid orange-7 over aluminum oxide nanoparticles," Journal of Engineering, vol. 2013, Article ID 593534, 8 pages, 2013.

[11] J. Li, Y. Shi, Y. Cai, S. Mou, and G. Jiang, "Adsorption of di-ethylphthalate from aqueous solutions with surfactant-coated nano/ microsized alumina," Chemical Engineering Journal, vol. 140, no. 1-3, pp. 214-220, 2008.

[12] A. R. Türker, "New sorbents for solid-phase extraction for metal enrichment," Clean, vol. 35, no. 6, pp. 548-557, 2007.

[13] L. Zhang, T. Huang, M. Zhang, X. Guo, and Z. Yuan, "Studies on the capability and behavior of adsorption of thallium on nano$\mathrm{Al}_{2} \mathrm{O}_{3}$," Journal of Hazardous Materials, vol. 157, no. 2-3, pp. 352$357,2008$.

[14] Y. C. Sharma, V. Srivastava, S. N. Upadhyay, and C. H. Weng, "Alumina nanoparticles for the removal of $\mathrm{Ni}$ (II) from aqueous solutions," Industrial and Engineering Chemistry Research, vol. 47, no. 21, pp. 8095-8100, 2008.

[15] M. Ghaedi, K. Niknam, A. Shokrollahi, E. Niknam, H. R. Rajabi, and M. Soylak, "Flame atomic absorption spectrometric determination of trace amounts of heavy metal ions after solid phase extraction using modified sodium dodecyl sulfate coated on alumina," Journal of Hazardous Materials, vol. 155, no. 1-2, pp. 121-127, 2008.

[16] S. Dadfarnia, A. M. H. Shabani, and H. D. Shirie, "Determination of lead in different samples by atomic absorption spectrometry after preconcentration with dithizone immobilized on surfactant-coated alumina," Bulletin of the Korean Chemical Society, vol. 23, no. 4, pp. 545-548, 2002.

[17] A. M. H. Shabani, S. Dadfarnia, and Z. Dehghani, "On-line solid phase extraction system using 1,10-phenanthroline immobilized on surfactant coated alumina for the flame atomic absorption spectrometric determination of copper and cadmium," Talanta, vol. 79, no. 4, pp. 1066-1070, 2009.

[18] A. Afkhami, M. Saber-Tehrani, and H. Bagheri, "Simultaneous removal of heavy-metal ions in wastewater samples using nanoalumina modified with 2,4-dinitrophenylhydrazine," Journal of Hazardous Materials, vol. 181, no. 1-3, pp. 836-844, 2010.

[19] A. Afkhami, M. Saber-Tehrani, H. Bagheri, and T. Madrakian, "Flame atomic absorption spectrometric determination of trace amounts of $\mathrm{Pb}$ (II) and $\mathrm{Cr}$ (III) in biological, food and environmental samples after preconcentration by modified nanoalumina," Microchimica Acta, vol. 172, no. 1, pp. 125-136, 2011.

[20] V. Srivastava, C. H. Weng, V. K. Singh, and Y. C. Sharma, "Adsorption of nickel ions from aqueous solutions by nano alumina: kinetic, mass transfer, and equilibrium studies," Journal of Chemical and Engineering Data, vol. 56, no. 4, pp. 1414-1422, 2011. 
[21] I. Langmuir, "The adsorption of gases on plane surfaces of glass, mica and platinum," The Journal of the American Chemical Society, vol. 40, no. 9, pp. 1361-1403, 1918.

[22] H. Freundlich and W. Heller, "The adsorption of cis- and tramazobenzene," Journal of the American Chemical Society, vol. 61, no. 8, pp. 2228-2230, 1939.

[23] S. Lagergren, "On the theory of so called adsorption of dissolved substances," Handlingar, vol. 24, pp. 1-39, 1898.

[24] Y. S. Ho, G. McKay, D. A. J. Wase, and C. F. Forster, "Study of the sorption of divalent metal ions on to peat," Adsorption Science and Technology, vol. 18, no. 7, pp. 639-650, 2000.

[25] W. J. Weber and J. C. Morris, "Kinetics of adsorption of carbon from solution," Journal of the Sanitary Engineering Division, vol. 89, no. 2, pp. 31-59, 1963.

[26] Z. Aksu, "Determination of the equilibrium, kinetic and thermodynamic parameters of the batch biosorption of nickel(II) ions onto Chlorella vulgaris," Process Biochemistry, vol. 38, no. 1, pp. 89-99, 2002.

[27] Y.-S. Ho, "Selection of optimum sorption isotherm," Carbon, vol. 42, no. 10, pp. 2115-2116, 2004.

[28] S. Brunauer, P. H. Emmett, and E. Teller, "Adsorption of gases in multimolecular layers," Journal of the American Chemical Society, vol. 60, no. 2, pp. 309-319, 1938.

[29] D. J. Yang, B. Paul, W. J. Xu et al., "Alumina nanofibers grafted with functional groups: a new design in efficient sorbents for removal of toxic contaminants from water," Water Research, vol. 44, no. 3, pp. 741-750, 2010.

[30] A. L. Prasad and T. Santhi, "Adsorption of hazardous cationic dyes from aqueous solution onto Acacia nilotica leaves as an eco friendly adsorbent," Sustainable Environment Research, vol. 22, no. 2, pp. 113-122, 2012.

[31] M. A. Al Da'amy, E. T. Al Rubaeey, A. B. Al Khaleeli, M. N. Abdul Majeed, and Z. A. Al Njar, "Adsorption of cationic dyes from synthetic textile effluent by Iraqi porcelanite rocks," Journal of Asian Scientific Research, vol. 3, no. 10, pp. 1011-1021, 2013.

[32] F. S. Abbas, "Dyes removal from wastewater using agricultural waste," Advances in Environmental Biology, vol. 7, no. 6, pp. 10191026, 2013.

[33] A. L. Narayanan, M. Dhamodaran, and J. S. Solomon, "Thermodynamics and kinetics of adsorption of Alizarin yellow from aqueous solutions on Saccharum spontaneum," International Journal of Engineering and Applied Sciences, vol. 2, no. 2, pp. 6369, 2015.

[34] E. S. Z. E. Ashtoukhy, "Loofa egyptiaca as a novel adsorbent for removal of direct blue dye from aqueous solution," Journal of Environmental Management, vol. 90, no. 8, pp. 2755-2761, 2009.

[35] E. Bulut, M. Özacar, and I. A. Şengil, "Adsorption of malachite green onto bentonite: equilibrium and kinetic studies and process design," Microporous and Mesoporous Materials, vol. 115, no. 3, pp. 234-246, 2008.

[36] R. E. Treybal, Mass Transfer Operations, McGraw-Hill, New York, NY, USA, 2nd edition, 1968.

[37] T. Santhi, S. Manonmani, and T. Smitha, "Removal of malachite green from aqueous solution by activated carbon prepared from the epicarp of Ricinus communis by adsorption," Journal of Hazardous Materials, vol. 179, no. 1-3, pp. 178-186, 2010.

[38] B. H. Hameed, "Spent tea leaves: a new non-conventional and low-cost adsorbent for removal of basic dye from aqueous solutions," Journal of Hazardous Materials, vol. 161, no. 2-3, pp. 753-759, 2009.
[39] M. U. Ibezim-Ezeani and A. C. I. Anusiem, "Thermodynamics of the adsorption of palmitate and laurate soaps onto some metal ore surfaces in aqueous media," African Journal of Pure and Applied Chemistry, vol. 5, no. 9, pp. 272-277, 2011.

[40] J. Li, Y. Shi, Y. Cai, S. Mou, and G. Jiang, "Adsorption of di-ethylphthalate from aqueous solutions with surfactant-coated nano/ microsized alumina," Chemical Engineering Journal, vol. 140, no. 1-3, pp. 214-220, 2008. 

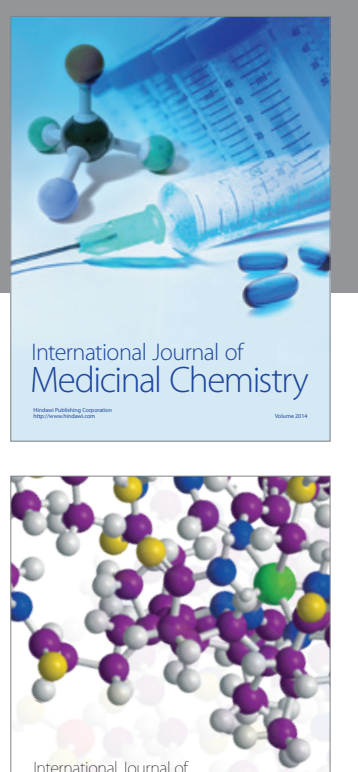

Carbohydrate Chemistry

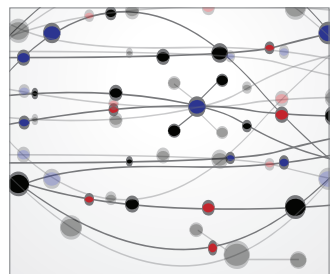

The Scientific World Journal
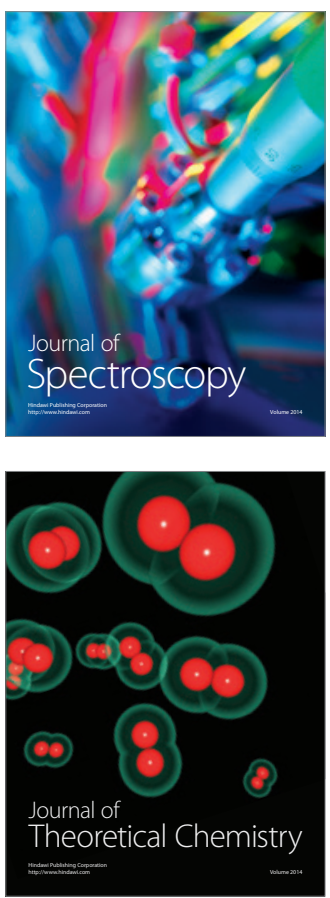
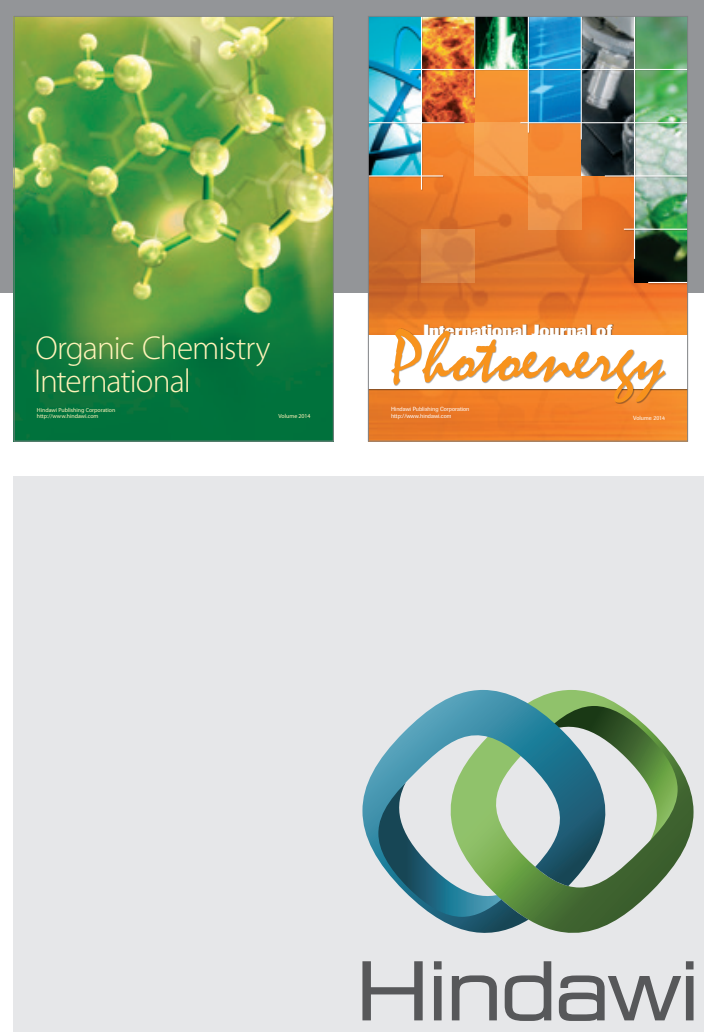

Submit your manuscripts at

http://www.hindawi.com

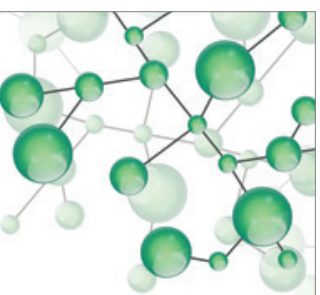

International Journal of

Inorganic Chemistry

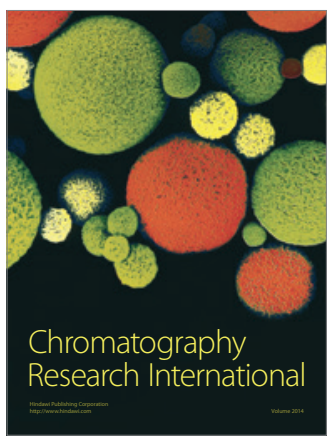

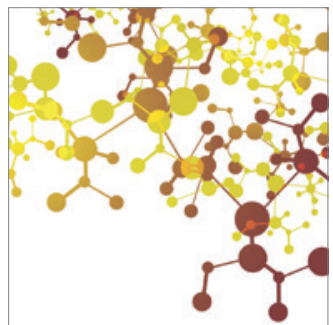

Applied Chemistry
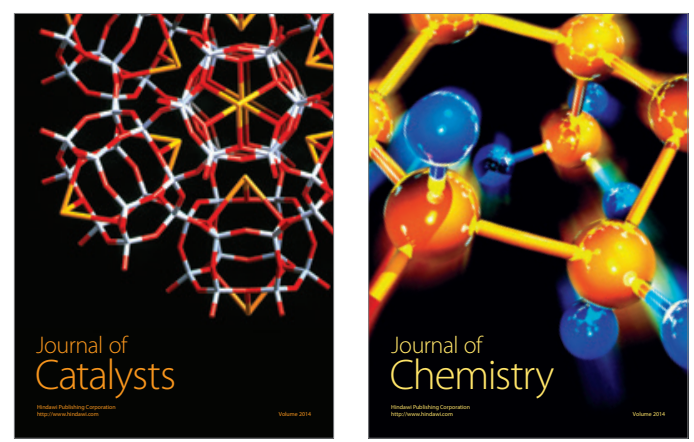
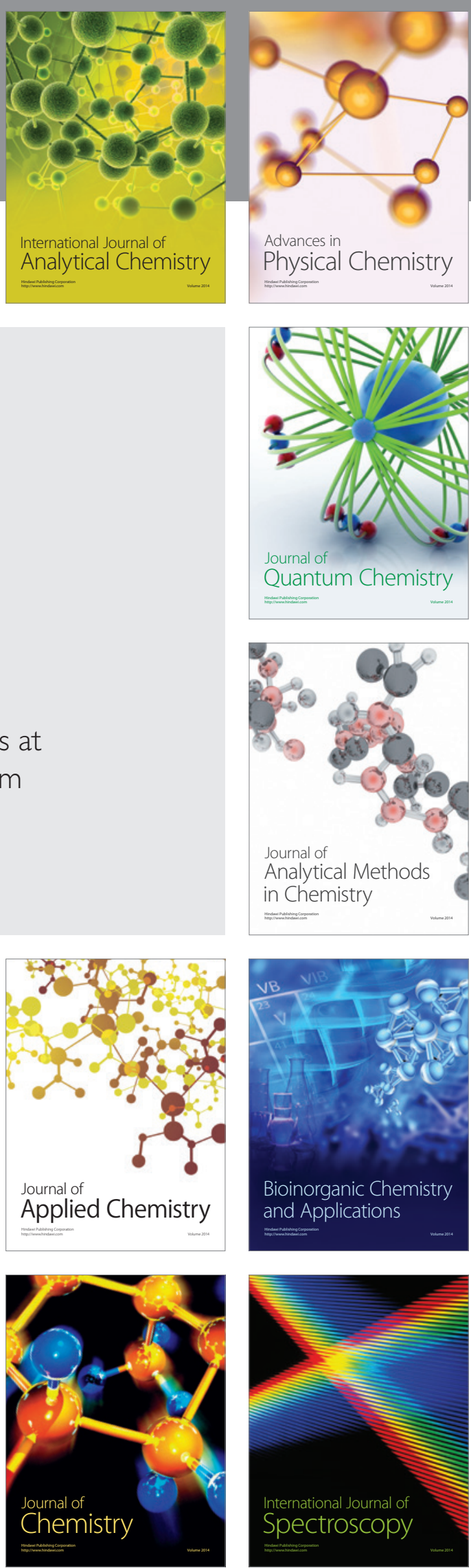